\title{
A Unesco e o projeto de criação de um laboratório científico internacional na Amazônia ${ }^{1}$
}

\author{
MARCOS CHOR MAIO
}

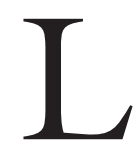

OGO APÓs O FIM da Segunda Guerra, a Organização das Nações Unidas para a Educação, Ciência e Cultura (Unesco) constituiu-se em locus privilegiado da discussão acerca da destinação social da ciência em regiões periféricas. Esse debate ocorreu sob o impacto dos efeitos do conflito mundial e diante de determinados desafios, tais como: fome, refugiados, desequilíbrios ambientais e desigualdades socioeconômicas. $\mathrm{O}$ interesse pela pesquisa da riqueza biológica e ecológica dos biomas de florestas úmidas tropicais foi um dos pontos da agenda científica e política da instituição, que se traduziu em projetos como o da criação de um laboratório científico internacional na Amazônia. Sob os auspícios da Divisão de Ciências Naturais, o plano de fundação do Instituto Internacional da Hiléia Amazônica (IIHA) foi um dos quatro principais projetos da Unesco para o ano de 1947 (Maio e Sá, 2000).

Há uma espécie de consenso na literatura acerca do alegado fracasso do plano do IIHA em função das dificuldades políticas enfrentadas no Brasil, na medida em que o plano foi considerado uma ameaça à soberania nacional. Este fato seria um indicador preciso da falta de experiência política da Unesco no início de suas atividades em face de um projeto de tal magnitude e da importância das forças nacionalistas no Brasil (Laves e Thomson, 1968 [1957]; Crampton, 1972).

As versões sobre a “derrota” do projeto IIHA perdem de vista uma trajetória bem mais complexa e matizada. O processo de formulação e decisão de propostas em fóruns internacionais e a recepção em nível nacional é marcado por dinâmicas de compartilhamento, conflito e negociação entre os níveis internacional e nacional; circulação de idéias e concepções de políticas entre elites dirigentes, burocracias e intelectuais. Este texto, por conseguinte, tem por objetivo apresentar alguns aspectos da recepção de um projeto da Unesco no pós-guerra, observando como se desenvolveu as interações entre demanda global e resposta local. Sugere-se que determinadas propostas internacionais foram centrais na formulação de projetos nacionais, que, no entanto, não se confundem com as concepções originais, seguindo, até certo ponto, uma lógica autóctone (Maio, 2004). Nesse sentido, o plano de criação do Instituto da Hiléia foi um catalisador de temas e problemas candentes, que geraram um efeito não antecipado, ou seja, a criação do Instituto Nacional de Pesquisas da Amazônia (Inpa). 


\section{O início da Unesco e o internacionalismo científico}

A Unesco faz parte da rede de instituições intergovernamentais criada no pós-Segunda Guerra. Sua declaração de princípios contida no preâmbulo da Constituição da Unesco reflete a busca de inteligibilidade dos motivos que levaram ao conflito mundial. Conforme a visão liberal da instituição, na medida em que "as guerras começam nas mentes dos homens, é nas mentes dos homens que os baluartes da paz devem ser erguidos" (Huxley, 1946, p. 5). Para realizar tal tarefa, os líderes da Unesco julgavam necessário "assegurar para todos pleno e igual acesso à educação, à livre busca da verdade objetiva e à livre troca de idéias e de conhecimentos" (Finkielraut, 1995, p. 53). A Unesco postulava, dessa forma, a superação da ignorância, do preconceito e do nacionalismo xenófobo, por meio da educação, da cultura e da ciência, e erigia como seu objetivo a criação de um consenso em torno de um mundo mais convergente (Sathyamurthy, 1964, p. 23). Assim, mediante um enfoque iluminista e universalista, a instituição internacional apostava no pluralismo ideológico e político alicerçado numa solidariedade moral e intelectual. Afinal, o racionalismo e o humanismo, que permeavam tanto os ideais do capitalismo liberal quanto os do socialismo marxista, encontravamse em radical oposição ao nazifascismo (Hobsbawn, 1996, p. 20).

A ciência, nesse processo, assumiria papel central na construção de um mundo liberal-democrático. No plano das ciências naturais, mesmo antes do término da guerra, cientistas liderados pelo bioquímico inglês Joseph Needham, participaram de uma série de fóruns, na perspectiva de assegurar que o primado da colaboração científica internacional viesse a ser assegurado no pós-guerra (Needham, 1949, pp. 19-21). A introdução da ciência em igualdade de condições com a educação e a cultura nesse processo de discussão sobre a estrutura da nova agência, que redundaria na Unesco, resultou, em grande parte, da tragédia produzida pelas bombas atômicas norte-americanas em solo japonês. Em novembro de 1945, no discurso de abertura da conferência de Londres que instituiu a Unesco, Ellen Wilkinson, ministra da Educação da Inglaterra, declarava que nestes dias, quando todos imaginam, talvez apreensivamente, o que os cientistas farão conosco em seguida, é importante que eles estejam próximos das ciências humanas e que devam se conscientizar de suas responsabilidades perante a humanidade no que tange aos seus afazeres científicos (apud Finnemore, 1996, p. 48).

Este discurso chancelava a inserção da ciência na Unesco. Ele era um indicador preciso da força da comunidade científica internacional e de sua habilidade, no plano mundial, em lidar com questões como Hiroshima e Nagasaki. A Unesco deveria ser um importante instrumento para fomentar determinados constrangimentos éticos e morais às atividades dos cientistas na medida em que a associação entre ciência e Estado em tempos de guerra havia gerado uma série de efeitos perversos.

Para cientistas-intelectuais como o biólogo Julian Huxley, primeiro diretor-geral da instituição, ou o bioquímico Joseph Needham, engajados na cons- 
trução da Unesco, o desafio encontrava-se no difícil arranjo institucional entre uma agência intergovernamental e o princípio do não-governamentalismo. Para eles, a ciência não deveria ser controlada pelos Estados-membros. O desenvolvimento do conhecimento científico e sua difusão não estariam limitados às fronteiras nacionais. Tratava-se de um experimento transnacional. Além dos perigos presentes na possibilidade de o Estado explorar descobertas científicas para fins militares, havia também um antigo consenso, que inspirava uma "ideologia da ciência", analisada pelo sociólogo Robert Merton (1942), de que a interferência estatal inibia o progresso científico. A ciência seria mais eficaz se suas atividades estivessem sob o controle dos próprios cientistas. O programa da Divisão de Ciências Naturais aprovado na primeira sessão da Conferência Geral da Unesco, em novembro de 1946, confirmava o princípio da não intervenção estatal. Ele se expressou nas seguintes propostas aprovadas: 1) estabelecer uma ampla rede de escritórios de cooperação científica; 2) apoiar financeiramente associações científicas e ajudar seus membros em suas pesquisas; 3 ) coordenar o trabalho de divulgação, de circulação de informações científicas; 4) informar ao público de todos os países as implicações internacionais das descobertas científicas; 5 ) criar novas formas de cooperação científica internacional como, por exemplo, laboratórios científicos (Finnemore, 1996, pp. 49-50). Por fim, é importante ressaltar que este programa tinha uma forte inspiração no "princípio de periferia", princípio esse formulado pelo bioquímico Joseph Needham, Diretor da Divisão de Ciências Naturais da Unesco entre 1946 e 1948.

A experiência de Needham na China na Segunda Guerra Mundial (modernização de laboratórios, atualização de bibliotecas, publicação de produção científica chinesa em revistas especializadas do Ocidente etc.) sedimentou a crença no projeto de irradiação da ciência do centro para a periferia em escala ampliada sob a chancela da Unesco. Este movimento em direção à periferia estava identificado com as crenças socialistas que norteavam a militância de Needham (Werskley, 1988). O projeto do Instituto da Hiléia Amazônica era a outra China a ser descortinada pelo "princípio de periferia" (Maio e Sá, 2000).

\section{Uma utopia científica na Amazônia? Controvérsias em torno do projeto IIHA}

Em maio de 1946, a proposta do engenheiro-químico brasileiro Paulo Estevão de Berrêdo Carneiro (1901-1982) de criação de um centro de pesquisas na Amazônia foi inserida no programa científico em elaboração pelo Comitê de Ciências Naturais da Comissão Preparatória da Unesco, sob a coordenação de Joseph Needham. Referindo-se à magnitude da região amazônica, à importância de suas reservas hídricas, florestais e, em especial, ao seu valor científico e econômico, Paulo Carneiro ressaltava a urgência de se realizarem pesquisas no campo da botânica, da zoologia, da química, da geologia, da meteorologia, da antropologia e da medicina. Mencionava ainda a relevância de se estudar a população indígena da região. A proposta incluía os países com interesses imediatos na 
região: Bolívia, Peru, Colômbia, Equador, Venezuela, França, Grã-Bretanha e Países Baixos (Carneiro, 1951).

O plano tinha as marcas da trajetória científica e política de Paulo Carneiro. Oriundo de família que deitava raízes na elite imperial, educado em ambiência positivista, formado pela Escola Politécnica do Rio de Janeiro e pesquisador dos princípios ativos do guaraná e do curare, com experiência de estudo e trabalho em Paris (Sorbonne e Instituto Pasteur), Paulo Carneiro exerceu também atividade política nos anos de 1930 como Secretário de Agricultura do Estado de Pernambuco, onde procurou implementar políticas redistributivas (produção de alimentos a baixos custos e reforma agrária). No plano internacional, viveu a experiência da Segunda Guerra Mundial, sofrendo a "internação" na Alemanha nazista. Ao retornar ao Brasil, participou de missões de cooperação intelectual e de criação de instituições intergovernamentais (ONU e Unesco), tornando-se representante do Brasil na Unesco em 1946. Suas preocupações com a Amazônia vinham desde os anos de 1930 quando, na condição de pesquisador do Instituto Nacional de Tecnologia, apresentou um plano de modernização do plantio e comercialização da borracha e da castanha na região amazônica ao Ministério do Trabalho, Indústria e Comércio. A proposta do Instituto da Hiléia Amazônica vinha ao encontro do debate acerca da redefinição do papel da ciência e da atuação dos cientistas no interior da Unesco (Maio, 2001).

$\mathrm{Na}$ primeira sessão da Conferência Geral da Unesco, em novembro de 1946, em Paris, Joseph Needham destacou os problemas do desenvolvimento da ciência em países subdesenvolvidos, em função do isolamento, do reduzido número de cientistas, sem estímulo e sem interlocução, das barreiras sociais e culturais (casta, tradição e costumes) e da falta de apoio por parte do poder público. A divisão do mundo needhamiano entre "zonas luminosas" e "zonas escuras" (Ásia, África e partes da América do Sul) devia-se apenas a circunstâncias históricas. Nessa perspectiva, caberia aos cientistas do mundo desenvolvido cooperarem na superação não somente do isolamento dos seus colegas das regiões periféricas, mas também das respectivas disparidades materiais e sociais ${ }^{2}$.

Dos cinco representantes brasileiros nessa conferência, três eram cientistas e mantinham estreitos vínculos com o Instituto Oswaldo Cruz (IOC): Miguel Ozório de Almeida, Carlos Chagas Filho e Olympio da Fonseca. Miguel Osório de Almeida, expoente da fisiologia experimental, não concordava com a configuração do mundo da ciência desenhada por Needham, que desconhecia a existência, nas denominadas "zonas escuras", de instituições científicas de excelência. Ele propunha estudos no campo da história da ciência para tornar inteligível os fatores que limitavam e/ou favoreciam o desenvolvimento da ciência na periferia. Miguel Ozório se indagava também acerca da plena aceitação, por parte dos cientistas, da universalidade da ciência. Mesmo que fosse admitido que os cientistas percebessem a ciência como resultado da cooperação internacional, não se poderia abstrair os sentimentos de pertença nacional que encarnariam esses próprios cientistas. Sem enfrentar esses desafios, com base em investigações 
históricas, continuar-se-ia a praticar uma espécie de "imperialismo científico" afeito aos países que só valorizavam o que seria realizado dentro das chamadas "zonas luminosas" . Assinalava ainda a importância das relações entre ciência e nação, que, no caso da América Latina e, particularmente, no Brasil, passava obrigatoriamente pelo Estado. O diagnóstico de Miguel Ozório antecipava divergências futuras, como a que ocorreu por ocasião da indicação do coordenador do projeto amazônico.

Em dezembro de 1946, foi aprovada na Conferência de Paris o projeto do IIHA e autorizada a criação de Escritórios de Cooperação Científica em diversas regiões subdesenvolvidas (América Latina, Ásia e África), materializando assim o "princípio de periferia”. A principal missão do Escritório Latino-americano de Cooperação Científica (ELACC) era a implementação do projeto IIHA ${ }^{4}$.

Desde o segundo semestre de 1946, a partir de diversos contatos com colegas da Universidade de Cambridge e do Escritório de Representação das Colônias Britânicas (Colonial Office), Joseph Needham, com a anuência de Julian Huxley, diretor-geral da Unesco, convidou Edred John Henry Corner para assumir a direção do ELACC. Corner, botânico inglês, com larga experiência em flora tropical, formou-se pela Universidade de Cambridge, e foi pesquisador do Jardim Botânico de Cingapura, sob mandato britânico, entre 1929 e 1946. Durante a Segunda Guerra Mundial, notabilizou-se pelos esforços de preservação de bibliotecas, coleções e instituições científicas e históricas na Malásia, no contexto da dominação japonesa no Sudeste Asiático. Ele assumiu a direção do ELACC em março de $1947^{5}$.

Needham julgava que sua bem-sucedida experiência chinesa era atribuída, em parte, ao trabalho coletivo empreendido por cientistas de países desenvolvidos em estreito contato com seus colegas das "zonas periféricas". Acreditava ainda que os dirigentes dos Escritórios Regionais da Unesco deveriam estar atentos ao perigo de lidarem apenas com burocratas - em vez de estabelecerem estreitos contatos com os "verdadeiros batalhadores da ciência" - em países caracterizados por uma frágil institucionalização da ciência e por uma estrutura política que atribuía pouca importância aos afazeres científicos (Science e Unesco, pp. 1920). Contudo, no caso da América Latina, certas contradições despontaram na implementação dos princípios needhameanos.

Em abril de 1947, o conselho executivo da Unesco decidiu que o IIHA passava a ser considerado um dos quatro principais projetos a ser implementado naquele ano. Na ocasião, Paulo Carneiro e outros representantes latino-americanos se opuseram à indicação de Corner em virtude da falta de sua familiaridade com a América do Sul, sua cultura e sua vida política. Carneiro tinha restrições à forma como estava sendo aplicado o "princípio de periferia". Para ele, à frente do Instituto da Hiléia, deveria estar um cientista de prestígio da América Latina. Em carta a Huxley, logo após a reunião do Conselho Executivo da Unesco, em Paris, Paulo Carneiro alertava: 
Não esqueça, senhor diretor-geral que os países sul-americanos são bastante exigentes e não apreciam ter a impressão de serem tratados como colônias às quais são enviadas missões de estudo das quais eles não façam parte desde o início ${ }^{7}$.

Paulo Carneiro percebia um acento colonialista na visão da conexão inglesa (Huxley, Needham), que pouco conhecia a América Latina e sua comunidade de cientistas, como já havia assinalado Miguel Ozório de Almeida. Ele acabou por ser indicado, como "consultor especial", por Julian Huxley, para estabelecer os elos de ligação entre a Unesco, a comunidade científica e o Estado brasileiro ${ }^{8}$.

A partir da Primeira Sessão da Conferência Geral da Unesco, o plano do IIHA deixou de ser apenas a proposta de um centro de pesquisas predominantemente voltado para a ciência básica, como estava previsto no projeto original. Por pressão dos países latino-americanos, ele passou a incorporar novas diretrizes nas áreas da educação, da cultura e da saúde. Este novo perfil causou certas preocupações por parte da Divisão de Ciências Naturais da Unesco, na medida em que a nova proposta transcendia sua competência e exigia apreciáveis recursos ${ }^{9}$.

As divergências no processo de estruturação do projeto IIHA prosseguiram na Conferência Científica de Belém, realizada entre 12 e 18 de agosto de 1947, que definiria as pesquisas a serem desenvolvidas e o formato da nova instituição. Com a presença de instituições nacionais e estrangeiras ${ }^{10}$, representando os países que tinham interesses na região, o fórum de Belém ofereceu subsídios ao programa do futuro Instituto da Hiléia, a partir do trabalho de três comissões ciências naturais; ciências sociais e educação; nutrição e ciências médicas. Algumas das propostas da Conferência de Belém diziam respeito à necessidade de amplo inventário faunístico e florístico, à criação de reservas florestais e sua exploração racional, à descoberta e à utilização de plantas de valor econômico, à cultura em terras inundáveis, ao desenvolvimento da piscicultura para fins alimentares, à criação bovina (em especial as raças adaptáveis ao meio amazônico), à pesquisa dos conhecimentos etnobotânicos dos povos indígenas, à realização de pesquisas antropológicas sobre as comunidades da região, à elaboração de inquéritos sociais tendo em vista o atendimento de demandas nos campos da educação e da saúde e ao fortalecimento de instituições científicas locais. Foram propostos estudos interdisciplinares a longo prazo, parcerias com instituições congêneres e com programas em curso, como o dos institutos e estações experimentais agrícolas já existentes na região. As propostas se assemelhavam a uma espécie de agenda de consenso sobre a Amazônia ${ }^{11}$.

As elites locais encaravam o projeto IIHA como uma alternativa a curto prazo, na medida em que os recursos previstos pela lei 199 da Constituição brasileira de 1946 ainda estavam no terreno das promessas. O discurso "internacionalista" do governador do Pará, Coronel Moura Carvalho, quando da abertura dos trabalhos da Conferência de Belém de 1947, revelava bem as preocupações amazônicas: 
A Amazônia é nossa, mas a serviço do mundo, a serviço da ciência, como fonte de trabalho e de bem-estar geral, como potencial capaz de produzir tudo quanto seja necessário aos outros povos, dentro do regime de fraternidade universal que deve presidir a todas as intenções na vida internacional (Carneiro, 1951, p. 24).

Após a reunião de Belém, Edred John Henry Corner elaborou um relatório para o Secretariado da Unesco. Nele, o botânico chamava a atenção para os poucos estudos sobre a hiléia e a falta de pesquisadores com a diversificação de conhecimento pretendida pela Unesco. A seu ver:

[...] o "S" em Unesco é o que todos desejamos.... "S" representa a ciência, quer sejam abstrações sobre prótons, genética ou sistemática, e não... tecnologia. Assim que o projeto científico for iniciado não se deve permitir sua degradação com o fim de conseguir apoio. Considero lamentável que a agricultura (que é uma política) e a educação (que é um fetiche histórico) ganhem precedência sobre a sede de conhecimentos sobre a região amazônica, a qual é uma atração interminável para cientistas ${ }^{12}$.

O relatório de Corner gerou apreensões no centro decisório da Unesco. A empolgação latino-americana expressa na agenda de pesquisas formulada em Belém escapava às expectativas e aos recursos da instituição. A partir do momento em que se procurou transformar uma demanda internacional (criação de um amplo centro de pesquisas) em projeto para solucionar problemas de uma região ávida por políticas públicas voltadas para o desenvolvimento regional, a direção geral da Unesco se viu diante de pressões, especialmente dos Estados Unidos. Os latino-americanos tinham um peso político expressivo no início da Unesco ${ }^{13}$, como se pode verificar não apenas pelos receios da direção da Unesco de criar qualquer tipo de suscetibilidade entre esses países, mas também pelo volume de recursos aprovados (cem mil dólares) para o projeto IIHA na Segunda sessão da Conferência Geral da Unesco realizada na cidade do México, em novembro de 1947, a despeito da oposição norte-americana ${ }^{14}$.

Responsáveis por parte substanciosa do orçamento da Unesco, os Estados Unidos estavam atentos ao binômio paz-segurança. Nutriam uma grande desconfiança em relação à intelligentsia internacionalista unesquiana, representada por Julian Huxley e Joseph Needham, e cobravam uma ação mais pragmática da instituição face ao contexto da Guerra Fria, da reconstrução européia e do avanço do socialismo. Pregavam a estreita relação política da Unesco com a ONU (Maio, 1998, pp. 378-379) ${ }^{15}$. Nesse sentido, a Amazônia ocupava, naquele momento, plano secundário aos olhos da política externa norte-americana, que primava pela visão ortodoxa do livre comércio, reiterando a posição do Brasil como exportador de matérias-primas estratégicas. Qualquer projeto voltado para o desenvolvimento regional era indesejado (Malan, 1984; Moura, 1990). Não por acaso, o botânico Corner, logo no início da estruturação do projeto IIHA informava a Paulo Carneiro que o futuro centro de pesquisas se assemelharia ao 
Smithsonian Institution, para que não restassem dúvidas aos norte-americanos "que o Instituto da Hiléia seria planejado para o aumento e disseminação do conhecimento, não originalmente para o desenvolvimento econômico" (grifo de Corner $)^{16}$. Assim, no final de 1947, na interpretação da representação norteamericana na Unesco, o perfil do projeto IIHA fugia à idéia de se constituir apenas em um laboratório científico internacional, demandando recursos apreciáveis da Unesco em cenário cheio de imprevisibilidades.

Apesar das adversidades enfrentadas na Conferência do México, foi estabelecido um cronograma de atividades que incluía a realização de uma convenção para estabelecer o estatuto legal do Instituto da Hiléia e a definição de um conjunto de pesquisas a serem efetuadas ao longo do ano de $1948^{17}$. Os constantes sinais de boas-vindas ao projeto IIHA, por parte de alguns países - Bolívia, Equador, Peru, Colômbia - não passaram de atos formais e inconclusos. Instabilidade política, ausência e/ou desencontro de informações, expectativas incompatíveis com as possibilidades materiais da Unesco, desconfianças acerca dos propósitos da organização internacional, resistências dos sul-americanos na alocação de recursos para o plano amazônico, disputas políticas pela hegemonia do projeto, entre o Brasil e o Peru, foram alguns dos aspectos presentes na Conferência de Iquitos (Peru), realizada em abril de 1948. Países como Holanda, Inglaterra e Estados Unidos não atribuíram maior importância ao evento. Conquanto a presença de uma ou outra personalidade sintonizada com o trabalho da Unesco ou, mais especificamente, com o projeto IIHA, como era o caso do etnólogo francês Paul Rivet, o fato é que a agência intergovernamental era pouco conhecida na América Latina e mobilizava, na região, limitados recursos humanos e financeiros ${ }^{18}$. O fórum de Iquitos revelou as fragilidades da proposta do Instituto da Hiléia no fronte interno latino-americano.

À crise do projeto IIHA no âmbito da Unesco acrescente-se a contenda gerada pela mensagem enviada pelo presidente Eurico Gaspar Dutra, em setembro de 1948, ao Congresso Nacional, na qual solicitava a ratificação do estatuto jurídico do futuro IIHA, elaborado pela Convenção de Iquitos, que deveria ser assinada por, pelo menos, cinco países envolvidos diretamente com a proposta. Este fato gerou um grande impacto no parlamento brasileiro, bem como na opinião pública, mobilizando militares, cientistas, jornalistas, intelectuais e entidades da sociedade civil. Radicalizaram-se as posições entre aqueles que defendiam a importância da cooperação internacional para o desenvolvimento da Amazônia e os que concebiam o projeto IIHA, sob a liderança do ex-presidente Arthur Bernardes, como a expressão dos interesses imperialistas sobre a região. Artigos e dispositivos da Convenção de Iquitos foram encarados como uma ameaça à soberania nacional, seja em função do grau de autonomia do IIHA em relação aos Estados-membros, seja porque minimizavam o peso político do Brasil no projeto. Houve até a assinatura de um protocolo adicional ao texto original, com o aval das Forças Armadas, para dirimir quaisquer dúvidas face às supostas 
ameaças à segurança nacional. No entanto, no início dos anos de 1950, a polarização política inviabilizou a criação do IIHA (Crampton, 1972, caps. 6 e 7).

A politização do projeto do Instituto Internacional da Hiléia Amazônica ocorre no momento em que a Unesco já havia reduzido significativamente seus investimentos no plano. Estava longe de representar a "cobiça internacional". Ademais, verificava-se simultaneamente um processo de redefinição das relações entre ciência, sociedade e Estado no Brasil, em função dos desdobramentos da Segunda Guerra Mundial. À emergência da questão nuclear, da defesa do petróleo e dos recursos minerais estratégicos como fundamento de um ambicioso projeto de superação do subdesenvolvimento e de afirmação do Brasil, por meio da ciência, como nação moderna, soma-se o debate em torno da criação de agências de fomento à pesquisa e o surgimento de novas associações científicas.

A comunidade dos físicos fundou, em 1949, o Centro Brasileiro de Pesquisas Físicas (CBPF) e, em estreita relação com os militares, criou, após dois anos, o Conselho Nacional de Pesquisas (Andrade, 1999, p. 15). Em 1948, os biólogos já haviam criado a Sociedade Brasileira para o Progresso da Ciência (SBPC). Esse movimento de institucionalização da ciência do pós-guerra tinha como esteio uma comunidade calçada em tradição advinda do IOC, do Instituto Biológico, do Instituto Butantã, da Universidade de São Paulo (USP), dos Institutos Agronômicos e de diversas associações científicas (Schwartzman, 1979, pp. 281 e 288).

O amplo debate público trouxe à tona o tema da Amazônia, sob a égide da aliança entre cientistas e militares. Após a criação do Conselho Nacional de Pesquisa (CNPq), em 1951, o almirante Álvaro Alberto, seu primeiro presidente, colocou na pauta da agência governamental a proposta do Instituto Nacional de Pesquisas da Amazônia (Inpa), que teria por "finalidade o estudo da geologia, da flora, da fauna, da antropologia e dos demais recursos naturais e das condições de vida da região amazônica, tendo em vista o bem-estar humano e os reclamos da cultura, da economia e da segurança nacional". Embora tivesse preocupação com a soberania nacional, o Inpa, criado em 1952 pelo decreto $\mathrm{n}^{\circ}$ 31672, espelhou-se, em grande parte, na proposta do IIHA e contou em sua gestação com a participação de diversos personagens envolvidos no projeto anterior: Paulo Carneiro, Heloísa Alberto Torres, Felisberto Camargo, Carlos Chagas Filho e Olympio da Fonseca (Fonseca, 1958, pp. 20-22; Weigel, 1994, caps. 4 e 5).

\section{Do IIHA ao Inpa: proposta global, respostas locais}

Visões distintas acerca do papel social da ciência, concepções contrastantes sobre as funções a serem exercidas pela Unesco, embates entre perspectivas universalistas e particularistas, dinâmicas diversas da profissionalização dos cientistas em "regiões periféricas" no pós-guerra, tensões da Guerra Fria, foram alguns dos aspectos revelados no processo de recepção da utopia amazônica de Paulo Carneiro. 
No final dos anos de 1940, quando o projeto IIHA estava em questão, ele gerou dois tipos de tradução. O primeiro deles, de natureza mertoniana, surgiu a partir da Conferência de Cientistas na América Latina, realizada em Montevidéu, em setembro de 1948, sob o patrocínio da Unesco. O fórum foi norteado pela busca de instrumentos para o desenvolvimento da ciência na América Latina por meio do fortalecimento de sua comunidade científica. Estavam presentes, como representantes do Brasil: Miguel Osório de Almeida (do IOC e vice-presidente da conferência), Joaquim Costa Ribeiro (Departamento de Física da Faculdade Nacional de Filosofia da então Universidade do Brasil e um dos articuladores da criação do CBPF) e Maurício Rocha e Silva (Instituto Biológico de São Paulo e presidente da recém-fundada Sociedade Brasileira para o Progresso da Ciência SBPC).

Miguel Osório de Almeida lembrou a divisão do mundo da ciência de Needham entre "zonas iluminadas" e "zonas escuras". Afirmava que "nas zonas escuras, nas quais surgem às vezes focos isolados de luz, está inserida a América Latina". Ironicamente, declarava que "não existem [...] métodos rigorosos de fotometria em questões desta natureza" ${ }^{19}$. Maurício Rocha e Silva foi assaz crítico e contundente a respeito do projeto IIHA. Ele acreditava que a ausência de cooperação científica era um dos empecilhos mais graves ao desenvolvimento da ciência nos países latino-americanos. Um programa consistente neste plano deveria basear-se no conhecimento preciso da gama de associações e instituições culturais e científicas existentes na região. Segundo suas próprias palavras,

Este trabalho deve ser iniciado imediatamente, mesmo antes de se pensar em efetuar qualquer trabalho de importância, como o planejado para a Amazônia e que vem indicado no memorandum da delegação brasileira, como Hiléia Amazônica. A meu ver, o levantamento científico da Amazônia deverá ser, em grande parte, levado a cabo, com o auxílio dos nossos grandes institutos científicos, já existentes no Rio de Janeiro, São Paulo e mesmo no Norte do Brasil $[\ldots]^{20}$.

Maurício Rocha e Silva não questionava a natureza internacional do IIHA, somente a qualificava. O papel da Unesco seria o de fomentar pesquisas na Amazônia mediante o apoio às instituições científicas já existentes. Uma comunidade científica latino-americana autônoma e com suporte material teria as credenciais necessárias para adentrar o laboratório amazônico. Desse modo, ele trazia no bojo de suas indagações a constatação da falta de referências por parte da agência intergovernamental à comunidade científica nacional.

O segundo cenário de tradução do projeto IIHA traz à tona a reedição da aliança entre cientistas e militares no contexto dos novos movimentos do associativismo profissional no campo científico (CBPF, SBPC) e da criação de uma agência estatal de fomento à pesquisa $(\mathrm{CNPq})$, sob a égide da rede da energia atômica, na chave nacional-desenvolvimentista. Não obstante a perspectiva pragmática da "aliança amazônica", sua base de sustentação, diferente da rede atômi- 
ca, não estava calcada em qualquer recurso estratégico ou descoberta científica na região que pudesse gerar uma "ideologia da Amazônia”, ou seja, um espaço imaginado no qual a ciência superaria todos as mazelas econômicas e sociais ${ }^{21}$.

Fruto das relações entre ciência e política, a proposta do Instituto Nacional de Pesquisas da Amazônia buscava afirmar um projeto de ciência nacional, patrocinado pelo Estado, sem, no entanto, perder a autonomia diante dos interesses desenvolvimentistas colocados em tela nos anos de 1950. Olympio da Fonseca declarava que

qualquer instituição científica ainda que tenha em vista atender aos reclamos da agricultura, da indústria, da saúde pública, da economia enfim, não conseguirá a longo prazo preencher suas finalidades se não tiver a suportálo o lastro da ciência básica ou pura, de pesquisa teórica e desinteressada ${ }^{22}$.

Em outro momento, o primeiro diretor do Inpa afirmava que

sem o concurso em larga escala de técnicos, especialistas e professores estrangeiros não é ainda, e por muito tempo não será possível organizar a pesquisa científica e tecnológica nos diversos domínios do conhecimento e na proporção que impõem a premência e a relevância dos problemas. [...] Esse modo de proceder representa apenas a continuação de uma antiga e prestigiosa tradição" (Fonseca, 1958, p. 25).

Fonseca tinha plena consciência de que a tradição do Instituto Oswaldo Cruz, patrocinada pelo Estado, resultava de uma estratégia tensa entre a ciência básica, que conferia a autonomia aos cientistas em seus afazeres, e a ciência aplicada, que vinha ao encontro do atendimento das demandas sociais no campo da saúde pública. Tanto ele como Álvaro Alberto combinavam a visão da ciência como um instrumento de civilização e a abordagem que veio a prevalecer no pós-Segunda Guerra, especialmente influenciada pela experiência norte-americana, de conceber a ciência básica num processo evolutivo, linear, ou seja,

a suposição de uma cadeia com uma ponta inicial na ciência pura, seguida pela aplicada, o desenvolvimento tecnológico, a inovação, levando, finalmente, ao progresso econômico e social. De acordo com esse modelo, então, era lógico imaginar que o investimento público na ciência de qualidade, mais cedo ou mais tarde, retornaria para a própria sociedade (Davyt e Velho, 2000, p. 99 $)^{23}$.

Não destoante dessa perspectiva, o segundo diretor do Inpa, Arthur Cezar Ferreira Reis, ao fazer um balanço de sua gestão, considerava que:

É preciso por um ponto final na literatura impressionista, de exageros, de entusiasmos fáceis, para dar lugar à literatura objetiva, que resulte da operação de campo, do trabalho de laboratório, da verificação e da reflexão de gabinete. Ora, essa é a tarefa que compete ao Inpa, criado justamente pelos que compreendem a necessidade e a urgência de um trabalho dessa natureza e desse porte. Nenhum investimento poderá ser feito na Amazô- 
nia sem que $[. .$.$] haja a segurança do conhecimento prévio. É preciso dar$ crédito ilimitado [ao Inpa], não se lhe exigindo soluções imediatistas, que não podem ser dadas sem que se comprometa a excelência dos resultados. Pesquisa, convém recordar, não se faz da noite para o dia, requer tempo, cautela, pertinácia, dedicação, entusiasmo, confiança [e] projeto firme [...]. Sem isso, poderá haver exotismo, sensacionalismo, nunca conclusão técnico-científica (Reis, 1958, pp. 9-11).

Observa-se, a partir dos relatórios dos primeiros diretores do Inpa, a reiteração de um perfil de instituição científica na Amazônia que não prescindisse da cooperação científica internacional e que estivesse calcada na ciência básica. Sem essas precondições, corria-se o perigo do empiricismo, do artificialismo de empreendimentos econômicos, em nome do desenvolvimento, sem se levar em conta o conhecimento das singularidades regionais.

Os processos de recepção e de apropriação do projeto do Instituto Internacional da Hiléia Amazônica, que trouxeram como uma de suas conseqüências a fundação do Inpa, não se confundem com uma visão paroquial, ditada por um nacionalismo exaltado. Os cenários amazônicos vislumbrados e seus desdobramentos práticos indicaram uma interação forte entre Estado e comunidade cientifica, interação esta que estava atualizada com o debate internacional sobre a ciência no pós-guerra. Haviam desafios específicos, envoltos por problemas geopolíticos, embates da Guerra Fria e discussões acerca de um projeto nacional. O "processo antropofágico", que fomentou o surgimento do Instituto Nacional de Pesquisas da Amazônia, revelou, mais uma vez, que relações assimétricas no campo da ciência definidas pelo jogo das relações internacionais, como em qualquer outro campo, não prescindem de contatos culturais, de mediações sociais e políticas que manifestam diversas formas de tradução local.

\section{Notas}

1 Uma versão prévia deste texto foi apresentada no II Encontro da Associação Nacional de Pesquisa e Pós-graduação em Ambiente e Sociedade (ANPPAS), em maio de 2004.

2 Unesco/C/Prog. Com./S.C.Nat.Sci./V.R.1, p. 4-5, Arquivos da Unesco.

3 Unesco/C/Prog. Com./S.C.Nat.Sci./V.R.2, p. 10-1, Arquivos da Unesco.

4 General Conference, First Session, 1946. Paris, 1947, p. 272 e 274, Arquivos da Unesco.

5 E. J. H. Corner Papers, Arquivos da Unesco.

6 Unesco/Cons.Exec./2 ${ }^{a}$ Sess./S.R.6/1947 (rev.), 7.5.1947, pp. 1-4; Nat. Sci./Lat. Am./Hyl./1, 28.5.1947, p. 3, em REG 330.19 (8) A 01 I.I.H.A., Parte l até 31/ XII/1947 (Caixa 166, pasta 1); Unesco/Cons.Exec./2 ${ }^{\mathfrak{a}}$ ess./S.R.5/1947 (rev.), 7.5.1947, pp. 13-14, Arquivos da Unesco.

7 Carta de Paulo Carneiro a Julian Huxley, 16.4.1947, pp. 2-3, REG 330.19 (8) A 01 I.I.H.A., Parte 1 até 31/XII/1947 (Caixa 166, pasta 1), Arquivos da Unesco. 
8 Unesco/Cons.Exec./2a Sess./S.R.5/1947 (rev.), 7.5.1947, pp. 13-14, Arquivos da Unesco; Julian, Huxley "Memorandum on Question of Special Consultant from Brazil for the Hylean Amazon Project", 25.4.1947, 2 p.; carta de J. Huxley a P. Carneiro, 12.5.1947, 2 p., em REG 330.19 (8) A 01 I.I.H.A., Parte 1 até 31/XII/ 1947 (Caixa 166, pasta 1), Arquivos da Unesco.

9 Memorandum of Instructions to dr. Corner for guiadance at the Meeting of the Belem Commission, including Notes on the Agenda, 30.7.1947, 6 p. em REG 330.19 (8) A 01 I.I.H.A., Parte 1 até 31/XII/1947 (Caixa 166, pasta 1), Arquivos da Unesco.

10 Ao fórum de Belém vieram representantes do Museu Nacional, da Escola Nacional de Agronomia, do Museu Paulista, do Instituto Agronômico do Norte, do Instituto Brasileiro de Geografia e Estatística (IBGE) e do Instituto Nacional de Tecnologia. Participaram também os seguintes países: Bolívia, Brasil, Colômbia, Equador, Estados Unidos, França, Grã-Bretanha, Peru e Venezuela. Além da Unesco, estiveram presentes as seguintes instituições internacionais: Organização Mundial de Saúde (OMS); Instituto Interamericano de Agricultura (Iaia); Organização para Alimentação e Agricultura (FAO); Repartição Sanitária Pan-Americana (PASB) e União PanAmericana (PAU). General Conference, Second Session, Report Presented By The International Commission For The International Hylean Institute, Paris, 26.9.1947, 2C/18, pp. 1-3, Arquivos da Unesco.

11 Projeto do Instituto Internacional da Hiléia Amazônica - Relatório da Comissão Científica Internacional reunida em Belém de 12 a 18 de agosto de 1947, pp. 1634, em Correspondência/Diversos No Exterior/Unesco (Delegação Brasileira)/ Ofícios (recebidos)/1947-1948/AHI - 80/4/01.

12 Carta de E. J. H. Corner a Purnell, 3.9.1947, p. 2, em REG 330.19 (8) A 01, IIHA, Parte 1 até 31/XII/1947 (Caixa 166, pasta 1), Arquivos da Unesco.

13 Dos 32 estados-membros da Unesco no final de 1947, por ocasião da Segunda Sessão da Conferência Geral da Unesco, doze eram latino-americanos, ou seja, mais de um terço da composição da instituição intergovernamental (Director-General Activities 1997-1998. Paris, 1998), Arquivos da Unesco.

14 Carta de J. Huxley a W. Laves, 22.9.1947, 2 p., em REG 330.19 (8) A 01, IIHA, Parte 1 até 31/XII/1947 (Caixa 166, pasta 1); Carta de F. Malina e W. Purnell a J. Needham, 1.9.1947, 3 p.; Carta de E. J. H. Corner a W. Purnell, 3.9.1947, p. 4; carta de J. Huxley a W. Leland, 18.9.1947, p. 3; carta de J. Huxley a W. Laves, 22.9.1947, 2 p., em REG 330.19 (8) A 01, IIHA, Parte 1 até 31/XII/1947 (Caixa 166, pasta 1); Cons. Exec./3rd. Sess./Sr 2 (ver.), 15/91947, p. 4; General Conference, Second Session, Report Presented By The International Commission For The International Hylean Institute, Paris, 26.9.1947, 2C/18, 20 p.; Unesco, General Conference, Second Session, International Hylean Amazon Institute, suggestion presented to the Executive Board by Paulo E. de Berredo Carneiro, Mexico City, 2C/99, 8.11.1947, 4 p.; Unesco, Executive Board, Fourth Session, Cons. Exec./4e Sess./SR/7, pp. 9-12; Cons. Exec./4e Sess./SR/7, pp. 2-8; 5.11.1947; Unesco, General Conference, Second Session, Working Party L - Natural Sciences, 2C/L/SR4, 15.11.1947, pp. 2-10; Records of the General Conference of the Unesco, Second Session, Mexico, 1947, vol.1, Proceedings. Paris, Unesco, 1949, pp. 41720, 525-30, Arquivos da Unesco. 
15 Para o ano de 1947, os EUA foram responsáveis por 44,03\% do orçamento da Unesco. No ano de 1948 , esta cifra passou a ser de $41,88 \%$. Ou seja, nos anos em que a Unesco esteve mais envolvida com o projeto IIHA, os norte-americanos tinham sob sua responsabilidade quase metade do orçamento da agência intergovernamental (Archibald, 1993, p. 123).

16 Carta de E. J. H. Corner para Paulo Carneiro, 28/5/1947, 1p., em Fundo Família Carneiro, DAD/COC/Fiocruz.

17 Foram realizadas duas pesquisas antropológicas: a primeira no rio Huallaga (Perú), da qual participaram o zoólogo mexicano Candido Bolivar, o botânico peruano Ramón Ferreyra, o antropólogo equatoriano Anibal Buitrón e o geógrafo norteamericano Edwin Doran; e a segundatrata-se de um estudo de comunidade realizada em Gurupá (Pará) pelo antropólogo norte-americano Charles Wagley, e seu orientando do curso de doutorado em antropologia da Universidade de Columbia e funcionário do Museu Nacional, Eduardo Galvão. Efetuou-se também uma pesquisa, em Washington e Bogotá, pelo botânico colombiano Enrique Perez-Arbelaez, tendo em vista a elaboração de um índice bibliográfico sobre a Hiléia Amazônica. Ex.Sec./IC/IIHA/7, E. J. H. Corner, Reporte sobre el Dessarrollo del Proyecto de Hilea Amazónica de Unesco, 1947-1948, en Sud-América presentado á La Tercera Conferencia General de la Unesco, 20.10.1948, pp. 10-11, em REG 330.19 (8) a 01 I.I.H.A, part III b (Caixa 167, pasta 2), Arquivos da Unesco.

18 Carta de E.J.H.Corner a Raul Fernandes, 26.12.1947, 1 p., Fundo Família Carneiro, DAD/COC/Fiocruz; Carta de E. J. H. Corner a W. Purnell, 19.12.1947, 3 p.; carta de E. J. H. Corner a W. Purnell, 19.12.1947, 2 p., em REG 330.19 (8) A 01, IIHA, Parte 1 até 31/XII/1947 (Caixa 166, pasta 1); Arenales' Report, I Promotion Work, p. 7, em REG 330.19 (8) A 01, IIHA, Parte 1 até 31/XII/1947 (Caixa 166, pasta 1), Arquivos da Unesco.

19 Conferencia de Expertos Científicos de América Latina, Unescco, 6.9.1948. Montevideo, Imprensa Rosgal, 1949, pp. 8-9.

20 Conferencia de Expertos Científicos de América Latina, Unesco, 6.9.1948. Montevideo, Imprensa Rosgal, 1949, pp. 13-14 e 16-17.

21 Ao comparar a "rede da energia atômica" com a formação de uma possível "rede amazônica" inspiro-me em Andrade (1999).

22 Exposição de Motivos nº 3, 25/11/1954, Manaus, Fonseca (1958, p. 135).

23 O relatório Vannevar Bush (Science, the Endless Frontier, 1945) teve papel decisivo neste contexto de valorização da ciência básica no pós-Segunda Guerra (Motoyama, 1985 , p. 35 ).

\section{Bibliografia}

ANDRADE, Ana Maria Ribeiro. Físicos, mésons e politica: a dinâmica da ciência na sociedade. São Paulo, Hucitec/Mast/CNPq, 1999.

ARCHIBALD, G. Les États-Unis et L'UNESCO 1944-1963. Paris, Publications de la Sorbonne, 1993. 
CARNEIRO, P. E. de B. O Instituto Internacional da Hiléia Amazônica: razões e objetivos de sua criação. Rio de Janeiro, s.e., 1951.

CRAMPTON, E. L. Brazilian Nationalism and the Defeat of the Internacional Institute of the Amazon Hylea. Tese de doutorado, The American University, 1972.

DAVYT, Amílcar e VELHO, Lea. "A avaliação da ciência e a revisão por pares: passado e presente. Como será o futuro? História, Ciências, Saúde-Manguinhos, vol. VII, n. 1, mar.-jun. 2000, pp. 93-116.

FINKIELKRAUT, A. The Defeat of the Mind. New York, Columbia University Press, 1995.

FINNEMORE, M. National Interests in International Society. Ithaca, Cornell University Press, 1996.

FONSECA, Olympio. Instituto Nacional de Pesquisas da Amazônia. Relatório Geral, Rio de Janeiro, s.e., 1958.

HOBSBAWN, E. A era dos extremos: o breve século XX. São Paulo, Companhia das Letras, 1996.

HUXLEY, J. UNESCO: Its Purpose and Its Philosophy. Paris, Unesco, 1946.

LAVES, W. H. C. e THOMSON, C. A. UNESCO: Purpose, Progress, Prospects. Bloomington, Indiana University Press, 1968[1957].

MALAN, Pedro Sampaio. "Relações econômicas internacionais do Brasil". HGCB, t. III, vol. 4, pp. 53-106. São Paulo, Difel, 1984.

MAIO, M. C. “O Brasil no concerto das nações: a luta contra o racismo nos primórdios da Unesco". História, Ciências, Saúde-Manguinhos, vol. V (2), 1998, pp. 375-413.

"A tradução local de um projeto internacional: a UNESCO, o CNPq e a criação do Instituto Nacional de Pesquisas da Amazônia", em FAULHABER, Priscila e TOLEDO, Peter Mann (orgs.). Conbecimento e fronteira: história da ciência na Amazônia. Brasília/Belém, Museu Goeldi/ Paralelo 15, 2001, pp. 51-81.

"Demandas globais, respostas locais: a experiência da Unesco na periferia no pós-2 a Guerra Mundial (1946-1952)", em MAIO, Marcos Chor (org.). Ciência, politica e relações internacionais: ensaios sobre Paulo Carneiro. Rio de Janeiro, Unesco/ Editora Fiocruz, 2004, pp. 145-168.

MAIO, M. C. e SÁ, M. R. "Ciência na periferia: a Unesco, a proposta de criação do Instituto Internacional da Hiléia Amazônica e as origens do Inpa". História, Ciências, Saude-Manguinhos, vol. 6 (supl.), 2000, pp. 975-1017.

MOURA, Gerson. O alinhamento sem recompensa: a politica externa do governo Dutra. Rio de Janeiro, CPDOC/FGV, 1990.

MERTON, R. "Science and Democratic Social Structure". Em Social Theory and Social Structure. New York, The Free Press of Glencoe, 1957[1942].

MOTOYAMA, S. (1985). "A gênese do CNPq", em Revista da Sociedade Brasileirade História da Ciência, no ${ }^{\circ}$, Julho-Dezembro, p. 27-46.

NEEDHAM, J. Science and International Relations. Oxford, Blackwell Scientific Publications, 1949. 
REIS, Arthur Cezar Ferreira. "Instituto Nacional de Pesquisas da Amazônia. Prestação de conta de um administração, pelo Diretor, o Dr. Arthur Cezar Ferreira Reis ”. Publicações Avulsas, Instituto Nacional de Pesquisas da Amazônia, n. 15, 1958.

SATHYAMURTHY, T. V. The Politics of International Cooperation: Contrasting Conceptions of UNESCO. Genève, Librairie Droz, 1964.

Science and Unesco: International Scientific Cooperation. London, The Pilot Press, 1946.

SCHWARTZMAN, Simon. Formação da comunidade científica no Brasil. São Paulo, Editora Nacional/Finep, 1979.

UNESCO AND SCIENCE (Unesco/Prep. Com./Nat.Sci. Com./12). London, The Pilot Press, 1946.

WEIGEL, Peter. Ciência e desenvolvimento: dificuldade de diálogo na experiência do Instituto Nacional de Pesquisas da Amazônia (INPA). Dissertação de mestrado, Belém, Núcleo de Altos Estudos Amazônicos/UFPA, 1994.

WERSKEY, G. The Visible College: A Collective Biography of British Scientists and Socialists of the 1930s. London, Free Association Books, 1988 [1978].

RESUMO - ESTE ARTIGO tem por objetivo analisar o debate em torno da proposta de criação do Instituto Internacional da Hiléia Amazônia (IIHA), patrocinada pela Organização das Nações Unidas para a Educação, Ciência e Cultura (Unesco) e, particularmente, as formas de recepção e apropriação do plano tanto nos fóruns da agência intergovernamental quanto em solo brasileiro. Esse processo contempla continuidades e rupturas. Não obstante os projetos do IIHA e do Instituto Nacional de Pesquisas da Amazônia (Inpa) guardarem semelhanças quanto às respectivas agendas de pesquisa, $\mathrm{o}$ interesse global sobre a região amazônica passou a ser balizado pela intervenção e controle político do Estado brasileiro e pelos anseios da comunidade científica local, sob a chancela do então Conselho Nacional de Pesquisas (CNPq).

ABSTRACT - THIS ARTICLE examines the discussion generated by the proposal to create the International Institute of the Hylean Amazon (IIHA), sponsored by Unesco in the late 1940s. It is especially focused on the ways in which the proposal was received and appropriated both in several forums linked to Unesco and in Brazil. This process was marked by both continuity and change. Despite the fact that there were similarities between the projects of the IIHA and the National Amazon Research Institute (Inpa), in terms of their research agendas, global interest in the Amazon region was since then limited by the intervention and political control of the Brazilian state and by the interests of the local scientific community, under the aegis of National Research Council (CNPq).

Palavras-chave: Amazônia, Ciência, Tecnologia, Instituições de Pesquisa.

Keywords: Amazon, Science, Technology, Research Institutions.

Marcos Chor Maio é pesquisador e professor do Programa de Pós-graduação em História da Ciência da Saúde (Casa de Oswaldo Cruz/Fiocruz).

Recebido em 28 de dezembro de 2004 e aceito para publicação em 26 de janeiro de 2005. 